\title{
Parental Experiences with Chemotherapy-Induced Alopecia among Childhood Cancer Patients in Indonesia
}

\author{
Stefanus Gunawan ${ }^{1}$, Chloe ten Broeke ${ }^{2}$, Peter van de Ven ${ }^{3}$, Marijn Arnoldussen², \\ Gertjan Kaspers ${ }^{2}$, Saskia Mostert ${ }^{2 *}$
}

\begin{abstract}
Background: This study assessed parental experiences with chemotherapy-induced alopecia among children with cancer treated at an Indonesian academic hospital. Materials and Methods: Fifty parents of childhood cancer patients were interviewed using semi-structured questionnaires. Results: The moment that hair fell out was the moment that parents $(84 \%)$ had to admit their child had cancer. Alopecia was a traumatizing painful experience $(46 \%)$. Active strategies to hide alopecia, mainly hats, were used by $66 \%$ of children, while $34 \%$ never covered their bald head. If money had not been an issue, $40 \%$ would use another strategy. Alopecia made children limit outdoor daily activities $(78 \%)$ and engagement with others $(60 \%)$. Significantly more children from high-educated $(95 \%)$ than low-educated $(60 \%)$ parents received sympathy from other people $(P=0.012)$. Significantly more Christian $(\mathbf{2 9} \%)$ than Muslim (0\%) families confirmed that alopecia lowered the quality of life $(\mathrm{P}=0.046)$. Most parents $(\mathbf{8 2} \%)$ had no prior plans about alopecia management, yet for significantly more girls $(26 \%)$ than boys $(0 \%)$ such plans existed $(P=0.044)$. Parents received most information about alopecia from other parents $(66 \%)$. Parents $(92 \%)$ needed more alopecia education from doctors. Of all school-attending children, $53 \%$ were bullied and $47 \%$ did not want to attend school due to alopecia. Significantly more high-educated than low-educated families received pity from teachers and pupils $(94 \%$ vs. $0 \%, P=0.004)$, and acceptance by pupils $(81 \%$ vs. $0 \%, P=0.021)$. Conclusions: Alopecia is a severe, far-stretching side-effect of chemotherapy with physical, psychological and social consequences for children and parents. Parents should be better informed about occurrence and impact of alopecia. Extra attention is required to facilitate children's return to school. Healthcare providers should facilitate optimal supportive care through open dialogue and provision of educational materials for parents, children and their community.
\end{abstract}

Keywords: Childhood cancer - alopecia - low-income country - Indonesia

Asian Pac J Cancer Prev, 17 (4), 1717-1723

\section{Introduction}

Chemotherapy-induced alopecia is a common sideeffect of some chemotherapy regimens. Most reports about chemotherapy-related alopecia come from adult cancer patients. It is considered as one of the most feared and traumatic side-effects in adult oncology patient care. The incidence of alopecia is estimated at $65 \%$ of adults with cancer (Trueb et al., 2009)

The literature on chemotherapy-induced alopecia in childhood cancer is scarce. Although adult oncology studies unanimously confirm that alopecia is perceived as a severe side-effect, the findings from the few pediatric oncology studies on side-effects and alopecia in high-and low-income countries are more diffuse.

In a Canadian study, parents did neither report chemotherapy-induced alopecia as the most prevalent nor as a severe symptom. (Dupuis et al., 2010). A Swedish study of treatment-related symptoms of children with cancer showed that the most prevalent symptom was alopecia, whereas the most distressing symptom was pain. (Heden et al., 2013).

Two previous studies at academic hospitals on two different islands in Indonesia revealed contrasting findings. Although on both islands alopecia was prevalent in most childhood cancer patients, parents on the island Java did not think alopecia was a severe side-effect in their child, whereas families on the island Sulawesi stated that hair loss following chemotherapy was by far the most severe side-effect of cancer treatment. Both islands and hospitals face similar socio-economic circumstances, yet an apparent cultural difference is that the population in Java is predominantly Muslim, whereas in Sulawesi Christian. (Sitaresmi et al., 2009; Gunawan et al., 2014).

The aim of this study was to assess parental experiences with chemotherapy-induced alopecia among Indonesian

${ }^{1}$ Department of Pediatrics, Prof, Dr RD Kandou Hospital, Manado, Indonesia, ${ }^{2}$ Department of Pediatric Oncology-Hematology, ${ }^{3}$ Department of Epidemiology and Biostatistics, VU University Medical Center, Amsterdam, the Netherlands *For correspondence: s.mostert@vumc.nl 
childhood cancer patients on the island Sulawesi. We explored specific challenges families face when their child has chemotherapy-induced alopecia, to better understand the needs of parents and patients.

\section{Materials and Methods}

\section{Setting}

Indonesia has approximately 250 million inhabitants, of whom $27 \%$ (67 million) are children younger than 15 years. (BPS, 2014). In low-income countries, 102 per million children under 15 years get cancer (Howard et al., 2008) resulting in an estimated 6,800 new childhood cancer cases each year in Indonesia.

Our study was executed at Prof. Dr. RD Kandou Hospital (KH) in Manado, Sulawesi, Indonesia. This academic hospital treats pediatric cancer patients from North-Sulawesi, Gorontalo, North-Maluku and WestPapua. This results in an estimated population of 5 million people, of whom 1.4 million are under 15 years of age. (BPS, 2014). In KH's service area, approximately 140 childhood cancer patients younger than 15 can be expected. However, only 25-30 children are diagnosed with cancer in KH per annum. The event-free survival in $\mathrm{KH}$ is $9 \%$, with an abandonment rate of $48 \%$. (Mostert et al., 2012).

The pediatric oncology department is situated as a separate clinic and the inpatient care unit can accommodate 18 patients. It is run by 2 pediatric oncologists, 17 nurses and 4-5 monthly-rotating residents. Three different hospital classes are distinguished: $1^{\text {st }}, 2^{\text {nd }}$ and $3^{\text {rd }}$ class, each with different conditions concerning quality of provided food and number of children per hospital room. At 1st class, the best conditions apply, and with lower rank, the conditions decrease as well. Nonetheless, treatment protocols and medical staff do not differ between wards. No education material about cancer, its treatment and side-effects, such as alopecia, is available. Interns provide information about cancer and side-effects to parents. However, interns rotate on a weekly basis.

In Indonesia three types of health-insurance can be identified: Askes for civil servants, Jamsostek for people working in private sector, and Jamkesmas for poor Indonesians without regular income. Patients are referred to a particular hospital class based on parental income and type of health-insurance. Patients with Askes-insurance go to $1^{\text {st }}$ or $2^{\text {nd }}$ class, depending on how important their parent's position is in government. Jamsostek-insured patients are referred to 2nd class, while Jamkesmas patients end up in 3rd class.

\section{Study design}

This cross-sectional study consisted of a semistructured questionnaire. The focus was to assess parental experiences with chemotherapy-induced alopecia among Indonesian childhood cancer patients. Participants were parents of childhood cancer patients who were hospitalized or visited the outpatient clinic at KH between September 2013 and February 2014 and who had received at least one cycle of alopecia-inducing chemotherapy. Alopeciainducing chemotherapeutics were cyclophosphamide, carboplatin, doxorubicin, dactinomycin, vincristine and etoposide. Parental educational status was classified as low (no education-junior high school) or high (senior high school-university), and was determined by the parent with the highest educational level. Parental financial status was classified as poor ( $3^{\text {rd }}$ class, no insurance/jamkesmas) or prosperous ( $1^{\text {st }} / 2^{\text {nd }}$ class, jamsostek/askes $)$, and was determined by assigned hospital class at diagnosis and type of health-insurance. An independent interviewer and assistant interviewed respondents. Most questions could be evaluated by parents on two, three or four-point rating scales. A panel of Dutch and Indonesian doctors made sure of relevant questions. The questionnaire was pilot-tested on five parents of childhood cancer patients for content, clarity of language and cultural sensitivities. Following the pilot-test, a few questions were linguistically clarified. Anonymity and confidentiality were guaranteed. All respondents gave informed consent. The study was approved by the Medical Ethical Committee of KH.

\section{Data analysis}

Data management and analysis was performed with SPSS for Windows version 21. Frequency distributions, median, means and standard deviations were calculated. Differences in socio-demographic and clinical characteristics between respondents and nonrespondents were compared using chi-square and Fisher's Exact tests. Parental experiences and socio-demographic characteristics were compared between groups (based on gender, phase of treatment, religion, parental educational status, parental financial status) using Mann-Whitney, chi-square and Fisher's exact tests. Distribution of scores on pairs of questionnaire items were compared using Wilcoxon rank-sum test.

\section{Results}

\section{Patient and parent characteristics}

Between September 2013 and February 2014, 61 childhood cancer patients met the inclusion criteria of our study. Parents of 50 children (response rate 82\%) were interviewed. Parents of 11 children (18\%) were not interviewed because the patient passed away before interview could take place $(64 \%)$, did not have alopecia yet $(27 \%)$, only visited clinic briefly and now live abroad (9\%). Respondents consisted of mothers $(68 \%)$, fathers $(26 \%)$, grandmothers $(4 \%)$ or both parents $(2 \%)$. No significant differences were found in age at diagnosis, gender or type of cancer between respondents $(n=50)$ and non-respondents $(n=11)$. Table 1 illustrates sociodemographic and clinical characteristics of patients and parents.

\section{Financial difficulties}

Families' monthly income ranged from 7-315 Euro. Monthly income decreased over the course of their child's treatment (56\%). Fathers (24\%) and mothers (36\%) lost their job during treatment, all due to their child's cancer. Families (36\%) were forced to sell valuables in order to solve financial problems: land $(22 \%)$, house $(6 \%)$ and other personal belongings (72\%). The costs of treatment 
Parental Experiences with Chemotherapy-Induced Alopecia Among Childhood Cancer Patients in Indonesia

resulted in financial difficulties (74\%) and debts (54\%).

\section{Experience of alopecia}

All 50 children had experienced alopecia. This alopecia either occurred in the past $(60 \%)$ or was ongoing $(40 \%)$. The hair loss was partial $(53 \%)$ or total $(43 \%)$. Few parents $(4 \%)$ did not know because the hair was cut completely once it started to fall out. Parents described their children also had loss of eyelashes (42\%) and nostril hair (12\%).

\section{Perception and attitudes towards alopecia}

Table 2 illustrates that more parents pay attention to what their child looks like than to how they look themselves $(\mathrm{P}<0.001)$. The way their child looks is also considered to be more important than how parents look themselves $(\mathrm{P}<0.001)$. Before their child had cancer most parents $(80 \%)$ perceived baldness as pitiful, yet few parents $(36 \%)$ associated baldness with cancer (Table 3). Alopecia was not a reason to hesitate starting chemotherapy for most parents $(86 \%)$, and all parents (100\%) were willing to do anything if it could acquire only a little life expectancy in their child. After undergoing alopecia though, more than half of parents $(54 \%)$ altered their attitude towards alopecia. They felt alopecia was a traumatizing and painful experience (46\%). In retrospect, significantly more Christian (24\%) than Muslim (0\%) families would avoid alopecia $(\mathrm{P}=0.015)$. Few parents $(4 \%)$ considered stopping or interrupting treatment due to the bad experience of alopecia. Would the cancer return, alopecia would be a reason for few parents to refuse $(6 \%)$ or hesitate $(8 \%)$ to give chemotherapy for the second time.

\section{Active strategies to hide alopecia}

Active strategies to hide alopecia from other people were used by $66 \%$ of patients: hats $(88 \%)$, scarves $(6 \%)$, wigs (3\%), and hairpieces (3\%). In total $34 \%$ of patients never covered their bald head. Management of alopecia was a financial burden to some parents (20\%). If money had not been an issue, $40 \%$ of parents would use another strategy: Some would use hats $(50 \%)$, scarves $(20 \%)$, wigs $(5 \%)$ and hairpieces $(5 \%)$ instead of nothing. Others, who now used hats, would then prefer scarves $(10 \%)$ or wigs (10\%).

\section{Distress due to alopecia}

Physical distress due to alopecia was: headache (30\%), dryness inside nose (26\%), nose pain (12\%), pain on scalp (12\%), difficulty to open eyes (16\%) and irritation on scalp (10\%). Psychological distress due to alopecia is illustrated in Table 4. Significantly more children from higheducated $(95 \%)$ than low-educated $(60 \%)$ parents received sympathy from other people $(\mathrm{P}=0.012)$. Significantly more Christian (29\%) than Muslim (0\%) parents expressed hopelessness $(\mathrm{P}=0.046)$. Social distress was illustrated by limiting outdoor daily activities (78\%), minimizing activities requiring engagement with others $(60 \%)$, and fear of other people's reaction prevented enjoying social life $(38 \%)$. Significantly more prosperous $(56 \%)$ than poor $(13 \%)$ parents did not want other people to know that their child has cancer $(\mathrm{P}=0.011)$. Alopecia lowered their child's quality of life (22\%). Significantly more Christian (29\%) than Muslim (0\%) families confirmed that alopecia lowered the quality of life $(\mathrm{P}=0.046)$.

\section{Preparedness for alopecia}

Before start of treatment, little trouble was expected from hair loss $(60 \%)$ and parents had difficulties imagining what hair loss would be like $(48 \%)$. The majority of parents received most information about alopecia from parents of other cancer patients $(66 \%)$. Other sources of information about alopecia were: doctor (14\%), internet $(6 \%)$, relatives $(4 \%)$, books $(4 \%)$, nurse $(2 \%)$, friends $(2 \%)$. Parents had no prior plans about management of alopecia (82\%). Significantly more parents of girls (26\%)

Table 1. Socio-Demographic and Clinical Characteristics of Parents and Patients $(n=50)$

\begin{tabular}{|c|c|}
\hline Socio-demographic and clinical characteristics & $\mathrm{n}(\%)$ \\
\hline \multicolumn{2}{|l|}{ Patient characteristics: } \\
\hline \multicolumn{2}{|l|}{ Age at diagnosis: } \\
\hline Mean \pm SD (years) & $5.4 \pm 3.5$ \\
\hline Range (years) & $1-15$ \\
\hline \multicolumn{2}{|l|}{ Gender: } \\
\hline Female & $23(46 \%)$ \\
\hline Male & $27(54 \%)$ \\
\hline \multicolumn{2}{|l|}{ Distribution types of cancer: } \\
\hline Acute lymphoblastic leukemia & $35(70 \%)$ \\
\hline Wilm's tumor & $6(12 \%)$ \\
\hline Retinoblastoma & $3(6 \%)$ \\
\hline Acute myeloid leukemia & $2(4 \%)$ \\
\hline Non-Hodgkin lymphoma & $2(4 \%)$ \\
\hline Rhabdomyosarcoma & $1(2 \%)$ \\
\hline Chronic myeloid leukemia & $1(2 \%)$ \\
\hline \multicolumn{2}{|l|}{ Hospital class at diagnosis: } \\
\hline $1^{\text {st }}$ class & $4(8 \%)$ \\
\hline $2^{\text {nd }}$ class & $5(10 \%)$ \\
\hline $3^{\text {rd }}$ class & $41(82 \%)$ \\
\hline \multicolumn{2}{|l|}{ Health-insurance: } \\
\hline Askes & $9(18 \%)$ \\
\hline Jamkesmas & $40(80 \%)$ \\
\hline No insurance & $1(2 \%)$ \\
\hline \multicolumn{2}{|l|}{ Phase of treatment: } \\
\hline On treatment & $25(50 \%)$ \\
\hline Completed treatment & $25(50 \%)$ \\
\hline \multicolumn{2}{|l|}{ Parent characteristics: } \\
\hline \multicolumn{2}{|l|}{ Marital status: } \\
\hline Married & $46(92 \%)$ \\
\hline Widowed & $2(4 \%)$ \\
\hline Divorced & $1(2 \%)$ \\
\hline Single mother & $1(2 \%)$ \\
\hline \multicolumn{2}{|l|}{ Number of children: } \\
\hline Mean \pm SD (children) & $2.3 \pm 1.1$ \\
\hline Range (children) & $1-5$ \\
\hline \multicolumn{2}{|l|}{ Religious background: } \\
\hline Christian & $38(76 \%)$ \\
\hline Muslim & $12(24 \%)$ \\
\hline \multicolumn{2}{|l|}{ Parental educational status*: } \\
\hline Low (no education - junior high school) & $10(20 \%)$ \\
\hline High (senior high school - university) & $40(80 \%)$ \\
\hline \multicolumn{2}{|l|}{ Parental financial status**: } \\
\hline Poor (3rd class, no insurance/jamkesmas) & $41(82 \%)$ \\
\hline Prosperous (1st/2nd class, jamsostek/askes) & $9(18 \%)$ \\
\hline
\end{tabular}

*Parental educational status: parent with highest educational level determines designated level $* *$ Parental financial status: based on assigned hospital class at diagnosis and type of health-insurance 
than boys $(4 \%)$ had prior alopecia plans $(\mathrm{P}=0.044)$. Most parents $(92 \%)$ reported to need more information from doctors on how to prepare and manage alopecia.

\section{Reaction of social network}

Table 5 presents the reaction of family's social network to the child's alopecia. Although almost all parents received support from family, friends, villagers and religious community members, some parents were disappointed in the response of relatives (45\%) and friends (38\%). Bad looks by friends (47\%), villagers $(40 \%)$ and religious community members $(36 \%)$ were reported. Significantly more high-educated than loweducated families received pity from friends $(100 \%$ vs. $71 \%, \mathrm{P}=0.021)$ and villagers $(100 \%$ vs. $78 \%, \mathrm{P}=0.033)$, and support and acceptance from villagers and religious community $(100 \%$ vs. $78 \%, \mathrm{P}=0.033)$.

\section{Reaction at school}

Of the 34 children of school-going age, parents $(65 \%)$ had openly discussed the cancer of their child at school. Alopecia had more often been openly discussed with teachers (44\%) than with pupils (26\%). Seventeen children $(50 \%)$ had attended school with apparent alopecia.

Table 2. Importance of Physical Appearance According to Parents $(\mathbf{n}=\mathbf{5 0})$

\begin{tabular}{|c|c|}
\hline Statement & $\mathrm{n}(\%)$ \\
\hline \multicolumn{2}{|l|}{ I pay attention to what I look like } \\
\hline Agree & $25(51 \%)$ \\
\hline Uncertain & $7(14 \%)$ \\
\hline Disagree & $17(35 \%)$ \\
\hline \multicolumn{2}{|c|}{ I pay attention to what my child looks like } \\
\hline Agree & $45(92 \%)$ \\
\hline Uncertain & $3(6 \%)$ \\
\hline Disagree & $1(2 \%)$ \\
\hline \multicolumn{2}{|c|}{ If my child looks good, it makes me feel good } \\
\hline Agree & $45(92 \%)$ \\
\hline Uncertain & $1(2 \%)$ \\
\hline Disagree & $3(6 \%)$ \\
\hline \multicolumn{2}{|l|}{ The way I look is: } \\
\hline Very important & $3(6 \%)$ \\
\hline Important & $19(39 \%)$ \\
\hline Not so important & $27(55 \%)$ \\
\hline \multicolumn{2}{|l|}{ The way my child looks is: } \\
\hline Very important & $19(40 \%)$ \\
\hline Important & $26(54 \%)$ \\
\hline Not so important & $3(6 \%)$ \\
\hline \multicolumn{2}{|c|}{$\begin{array}{l}\text { Table 3. Perception of Baldness Before Their Chil } \\
\text { Had Cancer According to Parents }(n=50)\end{array}$} \\
\hline Perception of baldness & $\mathrm{n}(\%)$ \\
\hline Pitiful & $40(80 \%)$ \\
\hline Never thought about it before & $32(64 \%)$ \\
\hline Ugly & $32(64 \%)$ \\
\hline Head is shaved & $31(62 \%)$ \\
\hline No specific perception & $27(54 \%)$ \\
\hline Sick person & $25(50 \%)$ \\
\hline Fashionable & $20(40 \%)$ \\
\hline Old age & $20(40 \%)$ \\
\hline Cancer patient & $18(36 \%)$ \\
\hline Cool & $14(28 \%)$ \\
\hline
\end{tabular}

The others $(50 \%)$ did not, because: children were still hospitalized/ too ill $(65 \%)$, hair had already regrown at time of school attendance (18\%), children stayed at home out of embarrassment for alopecia (12\%) and in one child alopecia was so well covered that nobody at school noticed it (6\%). Children (53\%) were bullied by pupils at school because of alopecia. This made their parents feel miserable (78\%) and cross (67\%). Parents reacted to bullying by speaking to teachers $(56 \%)$, pupils $(33 \%)$ or doing nothing $(11 \%)$. Many parents were disappointed in the reaction of pupils $(47 \%)$ and teachers $(41 \%)$ to alopecia. Some children $(47 \%)$ cried after coming out of school due to negative responses to alopecia and cancer. Children (35\%) and parents (35\%) were afraid of pupils' reaction to alopecia. Almost half of all children (47\%) did not want to go to school at all and in fact $53 \%$ limited school attendance because of alopecia. Significantly more high-educated than low-educated families received pity from teachers and pupils (94\% vs. $0 \%, \mathrm{P}=0.004)$, and acceptance by pupils $(81 \%$ vs. $0 \%, \mathrm{P}=0.021)$.

\section{Reaction of siblings}

The reactions of siblings to alopecia were acceptance (92\%), helpful (83\%), sad (72\%), bringing fewer friends to the house $(44 \%)$, frightened $(25 \%)$, teasing $(22 \%)$, depressed (19\%) and ashamed (17\%). Significantly more siblings with high-educated (82\%) than with low-educated (38\%) parents felt sad $(\mathrm{P}=0.024)$. Siblings had not been

Table 4. Psychological Distress Due to Alopecia According to Parents $(\mathbf{n}=50)$

\begin{tabular}{|c|c|}
\hline Statement & $\mathrm{n}(\%)$ \\
\hline Other people express pity & $46(92 \%)$ \\
\hline Other people express sympathy & $45(90 \%)$ \\
\hline $\begin{array}{l}\text { Moment that hair fell out, parents had to } \\
\text { admit child had cancer }\end{array}$ & $41(82 \%)$ \\
\hline Sadness & $35(70 \%)$ \\
\hline Crying & $31(62 \%)$ \\
\hline Guilty feelings about past unhealthy behavior & $26(52 \%)$ \\
\hline Frightened & $22(44 \%)$ \\
\hline Depressed & $21(42 \%)$ \\
\hline $\begin{array}{l}\text { Negative and uncomfortable attention from } \\
\text { other people }\end{array}$ & $14(28 \%)$ \\
\hline The thought that hair might not grow back & $14(28 \%)$ \\
\hline Powerless & $14(28 \%)$ \\
\hline Lowered self-esteem & $13(26 \%)$ \\
\hline $\begin{array}{l}\text { Anxious that hats/ scarves/ wigs/ hairpieces } \\
\text { fall of }\end{array}$ & $8(24 \%) *$ \\
\hline $\begin{array}{l}\text { Feelings of making other people } \\
\text { uncomfortable }\end{array}$ & $11(22 \%)$ \\
\hline Hopelessness & $11(22 \%)$ \\
\hline Ashamed & $10(20 \%)$ \\
\hline Anger & $10(20 \%)$ \\
\hline Loss of privacy & $8(16 \%)$ \\
\hline Other people avoid your child/family & $8(16 \%)$ \\
\hline
\end{tabular}


Table 5. Reaction of Social Network to the Child's Alopecia According to Parents ( $n=50)$

\begin{tabular}{|c|c|c|c|c|c|c|}
\hline Reaction: & $\frac{\text { Family }}{(n=49)}$ & $\frac{\text { Friends }}{(\mathrm{n}=45)}$ & $\frac{\text { Village community }}{(\mathrm{n}=47)}$ & $\frac{\text { Religious community }}{(\mathrm{n}=47)}$ & $\frac{\text { Teacher* }}{(n=17)}$ & $\frac{\text { Pupils* }}{(\mathrm{n}=17)}$ \\
\hline Pity & $96 \%$ & $96 \%$ & $96 \%$ & $94 \%$ & $88 \%$ & $88 \%$ \\
\hline Social support & $96 \%$ & $89 \%$ & $94 \%$ & $96 \%$ & $88 \%$ & $88 \%$ \\
\hline Acceptance & $94 \%$ & $91 \%$ & $96 \%$ & $96 \%$ & $88 \%$ & $88 \%$ \\
\hline Sympathy & $94 \%$ & $91 \%$ & $94 \%$ & $94 \%$ & $82 \%$ & $82 \%$ \\
\hline Disappointing & $45 \%$ & $38 \%$ & $30 \%$ & $28 \%$ & $41 \%$ & $47 \%$ \\
\hline Bad look & $39 \%$ & $47 \%$ & $40 \%$ & $36 \%$ & $24 \%$ & $29 \%$ \\
\hline Hurtful remark & $18 \%$ & $22 \%$ & $13 \%$ & $4 \%$ & $6 \%$ & $29 \%$ \\
\hline Ashamed & $8 \%$ & $16 \%$ & $11 \%$ & $9 \%$ & $6 \%$ & $29 \%$ \\
\hline Bullying & $4 \%$ & $20 \%$ & $6 \%$ & $0 \%$ & $0 \%$ & $53 \%$ \\
\hline Avoidance & $4 \%$ & $16 \%$ & $9 \%$ & $2 \%$ & $6 \%$ & $0 \%$ \\
\hline
\end{tabular}

*17 patients attended school with alopecia

Table 6. Lessons Learned Through the Process of Coping with Cancer-Related Alopecia According to Parents $(\mathbf{n = 5 0})$

\begin{tabular}{lc}
\hline \multicolumn{1}{c}{ Lessons } & $\mathrm{n}(\%)$ \\
\hline Accomplishing a life goal & $48(96 \%)$ \\
Appreciate small things in life more & $47(94 \%)$ \\
Increased interest in practicing religion & $47(94 \%)$ \\
Suffering can be a source of positive change & $47(94 \%)$ \\
Sense of personal strength & $47(94 \%)$ \\
Resilience & $47(94 \%)$ \\
Realized significance of having hair & $46(92 \%)$ \\
Increased feelings of closeness with family & $46(92 \%)$ \\
Focus on positive things in life for which you & $46(92 \%)$ \\
are thankful & $46(92 \%)$ \\
Improved interpersonal relationships & $46(92 \%)$ \\
Changes in how you live each day & $46(92 \%)$ \\
Spiritual development & $45(90 \%)$ \\
Better understand others in similar situations & $44(88 \%)$ \\
Overcoming a fear & $42(84 \%)$ \\
Increased feelings of closeness with friends & $39(78 \%)$ \\
Became more considerate about other people & $37(74 \%)$ \\
Awareness that life is hard & $22(44 \%)$ \\
Change in career & $20(40 \%)$ \\
New sense of vulnerability to death & $8(16 \%)$ \\
Support from others is disappointing & $5(10 \%)$ \\
\hline The process has made me bitter &
\end{tabular}

bullied themselves because their brother/sister has cancer or alopecia.

\section{Changes during and after alopecia}

The hair had started to grow again in the majority of children $(76 \%)$ at the time of interviewing. Baldness denotes being ill and novel hair after alopecia denotes hope and resumed life according to almost all parents (92\%). Once the hair starts to grow, parents $(94 \%)$ felt that the real treatment is completed, even though their child still has to take some medicines. Glancing at the novel hairs made parents $(92 \%)$ feel alive and joyful. Table 6 presents the lessons learned by parents through the process of coping with cancer-related alopecia. Significantly more families whose children were still on treatment $(88 \%)$ than those who had completed treatment $(63 \%)$ confirmed awareness that life is hard $(\mathrm{P}=0.030)$.

\section{Discussion}

Parents of children with cancer in our study found that the appearance of their children was more important than how parents looked themselves. Many parents never thought about alopecia prior to the diagnosis of cancer in their children and the majority of parents perceived baldness as pitiful or ugly. Only one third of parents related baldness with cancer. Once cancer invaded the lives of their children and hair loss occurred, more than half of parents changed their attitude towards alopecia. They now felt alopecia was a traumatizing and painful experience. After their children suffered from alopecia, many parents were sad, frightened and depressed. And at the moment the hair fell out, parents had to admit their child had cancer. Indeed, abundant studies reported that hair loss is one of the most traumatizing and distressing experiences for both patients with cancer and their family. However, most of these studies were from adults (Can et al., 2013; Choi et al., 2014; Kim et al., 2012; Jayde et al., 2013] and few from children with cancer. [Sadruddin et al., 2013; Williamson et al., 2010). The latter illustrated that parents felt that hair represented gender, youthfulness, health, and was part of their child's identity. Hair loss was a symbol of cancer. Before chemotherapy, indicators of their child's cancer were internal. But once the hair began to fall, the reality of the cancer struck home as the parent held physical evidence of their child's illness in their hands. (Williamson et al., 2010).

A substantial number of parents expressed physical, psychological and social distress of their child. They experienced their child limiting outdoor activities, minimizing engagement with others, and fearing reactions from other people. Previous studies also demonstrated that children with hair loss following chemotherapy avoided social activities to reduce embarrassment. They embraced coping strategies as social withdrawal and isolation (Williamson et al., 2010; Lee et al., 2012; Sadruddin et al., 2013). During this hard time parents', peers' and professionals' full reassurance and acceptance could enable them to overcome the distorted body image.

Significantly more Christian than Muslim families expressed hopelessness and stated that alopecia lowered their child's quality of life. Cultural and religious factors may also play an important role in coping with chemotherapy-induced alopecia. Muslim families, being more accustomed to using headscarves and covering body parts during their daily life, might have less body image problems than their Christian compatriots. Our study and a previous study in another part of Indonesia with a predominantly Muslim population support this view. 
[Sitaresmi et al., 2009] On the contrary, a study of Turkish women with cancer yielded different results. The Muslim women who wore headscarves prior to suffering from alopecia felt worse physically and psychologically than others. (Erol et al., 2012). This in turn shows the need of an individualized approach to patients with cancer.

More than $80 \%$ of parents had no prior plans about alopecia management and almost all reported to need more information from doctors on how to prepare and manage it. The majority of parents received most information about alopecia from other parents of children with cancer. Indeed, a previous study indicated that the greatest underestimation made by doctors regarding the worries of cancer patients was the hair loss problem. (Mulders et al., 2008). This underestimation may result in insufficient attention and failing guidance by medical staff how to best manage and cope with alopecia. (Ramirez et al., 2009).

Upon diagnosis doctors usually focus on the provision of treatment and survival. Several therapy-related sideeffects are discussed as well. At this point, doctors are placed in a dilemma of deciding which among many side-effects to discuss with parents. Burdening parents, who are distressed by their child's cancer diagnosis, with information about side-effects may, to some extent, be perceived as inappropriate. Nevertheless, proactively providing information and educational materials about diagnosis, treatment, and side-effects such as alopecia is recommended. Prior studies in adults show the important role of aesthetic care programs that aim to help cancer patients to bear the burden of chemotherapy-induced alopecia and provide information on what to expect with their hair loss and how to manage it. The aesthetic team may compose of doctors, nurses, educators, social workers, and hairdressers. (Deniffe et al., 2011; Zannini et al., 2012). When families are going through difficulties, proper guidance by professionals will encourage treatment adherence. (Williamson et al., 2010; Benedetti et al., 2014). Currently, the main reason for cancer treatment failure at $\mathrm{KH}$ is treatment abandonment, the most severe type of non-adherence, and ameliorated steering of families is therefore essential. (Mostert et al., 2012).

The most common strategies to cope with chemotherapy-induced alopecia are camouflaging and hiding. Wigs and hats are well known as being helpful. Other patients tend to accept alopecia as a logical consequence of chemotherapy and chose not to wear anything. The choice depends on gender, individual characteristics, social circumstances, and culture. (Trueb et al., 2010; Lee et al., 2012). This is in agreement with our results. Two-third of parents hid their child's hair loss, mostly using hats. If money had not been an issue, many parents would prefer to use camouflage instead of nothing. In our context, most families came from low socio-economic backgrounds and although the costs of hospitalization and chemotherapy was covered by government insurance, parents still suffered from financial difficulties and even debts. Therefore, families did not have much choice in providing proper strategies to cope with chemotherapy-induced alopecia.

We found a gender-based approach. Significantly more parents of girls than boys had prior alopecia plans.
This finding is probably a reflection of the view that for many women hair is a symbol of attractiveness, sexuality and femininity. Losing hair could be interpreted as losing some of the feminine characteristics. (Erol et al., 2012; Kim et al., 2012; Choi et al., 2014). Nonetheless, chemotherapy-related alopecia has indeed been found a difficult experience for both male and female patients. (Can et al., 2013; Al-Omari and Wynaden., 2014).

This study disclosed a generally positive response from the parents' social network to the child's alopecia, including relatives, friends, villagers and religious community. Yet, still a substantial number of parents were dissatisfied with the reaction of relatives and friends. Support from the social network is of utmost importance for parents and children to cope with cancer, appearance change, and to avoid long-term depression. (Sheng and Eiser., 2009; Hagerdoorn et al., 2011).

According to parents, the reaction of siblings towards the child with cancer were mostly acceptance, helpful as well as sad. Some siblings expressed being frightened and depressed. Few teased their brother/sister with cancer. None of the siblings had been bullied themselves due to their brother/sister having cancer or alopecia. These findings are interesting, since sibling rivalry has been known to exist among siblings of childhood cancer patients. Prior studies reported that most siblings experienced distress and school difficulty as well. (Alderfer et al., 2010; Hagedoorn et al., 2011; Kaplan et al., 2013).

On the contrary, the reaction from school, especially pupils, was less positive. Although more than half of parents had openly discussed the cancer of their child with teachers, approximately half of the children were bullied and cried after coming out of school due to negative responses to alopecia and cancer. As a result, the majority of parents felt miserable and angry. Half of all children did not want to go to school at all and in fact limited their school attendance. An earlier qualitative study reported that returning to school was particularly difficult for children with chemotherapy-altered appearance. [Williamson et al., 2010] Several techniques were described to overcome the negative reactions of friends or peers. Parental consolation and shielding, anticipatory warning to friends, responding with confidence and information are some of the strategies used. Notably, not all coping techniques could be applied to all scenarios, and the methods should be selected as best suited to each case. (Anderzen et al., 2010; Williamson et al., 2010; Lee et al., 2012).

When the hair returned after hair loss, more than $90 \%$ of parents felt alive and happy since new hair represents hope and renewed life. Parents felt that the real treatment is completed, although their child still has to take some medicines. Our results are in line with previous reports that parents and patients show a positive shift in their perception of life after experiencing and successfully managing chemotherapy-altered appearance, such as alopecia. They become more emotionally mature and can better understand the viewpoints of others. (Kim et al., 2012; Lee et al., 2012; Zannini et al., 2012). Nevertheless, significantly more parents whose children were still on treatment confirmed that life is hard compared to those 
who had completed treatment.

Limitations of this study entail the small sample size and the various treatment phases of the children. In addition, the Indonesian culture rejects criticism, especially of those placed higher in social hierarchy such as medical staff. (Magnis, 1997). This may have resulted in socially acceptable answers.

In conclusion, chemotherapy-induced alopecia is a severe, far-stretching side-effect of chemotherapy with physical, psychological and social consequences for both parents and children with cancer. Parents need guidance from doctors and nurses on how to manage hair loss in their children. Reactions toward alopecia from family, friends, and school varied. Many children were bullied by pupils and consequently limited school attendance. Extra attention is required to facilitate the children's return to school. These findings underline that health-care providers, who take care of children with cancer, need to better facilitate optimal supportive care, such as open dialogue and educational materials about the management of chemotherapy-induced alopecia. This guidance and informative tools should not only be implemented for parents and children, but also for their community.

\section{Acknowledgements}

We would like to thank Konda Tawaluyan, Julian Komansilan and Atika Winata for their assistance. We are grateful for the ongoing support of Stichting Medische Hulp Indonesië and SMALL Foundation.

\section{References}

Alderfer MA, Long KA, Lown EA, et al (2010). Psychosocial adjustment of siblings of children with cancer: a systematic review. Pychooncol, 19, 789-805.

Al-Omari O, Wynaden D (2014). The psychosocial experience of adolescents with haematological malignancies in Jordan: an interpretive phenomenological analysis study. Sci World $J, 5,274036$.

Anderzen-Carlsson A, Kihlgren M, Svantesson M, Sorlie V (2010). Parental handling of fear in children with cancer; caring in the best interests of the child. J Pediatr Nurs, 25, 317-26.

Benedetti GMS, Garanhani ML, Sales CA(2014). The treatment of childhood cancer: unveiling the experience of parents. Rev Latino-Am Enfermagem, 22, 425-31.

Biro Pusat Statistik (BPS). Statistical year book of Indonesia 2014. Available at: http://www.bps.go.id/hasil_publikasi/ SI_2014/index3.php?pub=StatistikIndonesia2014

Can G, Demir M, Erol O, Aydiner A (2013). A comparison of men and women's experiences of chemotherapy induced alopecia. Eur J Oncol Nurs, 17, 255-60.

Choi EK, Kim IR, Chang O, et al (2014). Impact of chemotherapyinduced alopecia distress on body image, psychosocial wellbeing, and depression in breast cancer patients. Psychooncol, 23, $1103-10$.

Deniffe S, Gooney M (2011). A meta-synthesis of women's symptoms experience and breast cancer. Eur J Cancer Care, 20, 424-35.

Dupuis LL, Milne-Wren C, Cassidy M, et al (2010). Symptom assessment in children receiving cancer therapy: the parents' perspective. Support Care Cancer, 18, 281-99.

Erol O, Can G, Aydmer A (2012). Effects of alopecia on body image and quality of life of Turkish cancer women with or without headscarf. Support Care Cancer, 20, 2349-56.

Gunawan S, Wolters E, van Dongen J, et al (2014). Parents' and health-care providers' perspectives on side-effects of childhood cancer treatment in Indonesia. Asian Pac J Cancer Prev, 15, 3593-9

Hagerdoorn M, Kreicbergs U, Appel C (2011). Coping with cancer: the perspective of patients' relatives. Acta Oncol, 50, 205-11.

Heden L, Poder U, von Essen L, Ljungman G (2013). Parents' perception of their child symptom burden during and after cancer treatment. J Pain Symptom Manage, 46, 366-75.

Howard SC, Metzger ML, Wilimas JA, et al (2008). Childhood cancer epidemiology in low-income countries. Cancer, 112, 461-72.

Jayde V, Boughton M, Blomfield P (2013). The experience of chemotherapy-induced alopecia for Australian women with ovarian cancer. Eur J Cancer Care, 22, 503-12.

Kaplan LM, Kaal KJ, Bradley L, Alderfer MA (2013). Cancerrelated traumatic stress reactions in siblings of children with cancer. Fam Syst Health, 31, 205-17.

Kim IR, Cho J, Choi EK, et al (2012). Perception, attitudes, preparedness and experience of chemotherapy-induced alopecia among breast cancer patients: a qualitative study. Asian Pac J Cancer Prev, 13, 1383-88.

Lee MY, Mu PF, Tsay SF, et al (2012). Body image of children and adolescents with cancer: a metasynthesis on qualitative research findings. Nurs Health Sci, 14, 381-90.

Magnis-Suseno F. Two basic principles of Javanese social life. Morality as knowledge of life (1997). In: Javanese ethics and world view: the Javanese idea of the good life. Jakarta: PT Gramedia; 42-83, 193-219.

Mostert S, Gunawan S, Wolters E, et al (2012). Socio-economic status plays important role in childhood cancer treatment outcome in Indonesia. Asian Pac J Cancer Prev, 13, 649196.

Mulders M, Vingerhoets A, Breed W (2008). The impact of cancer and chemotherapy: perceptual similarities and differences between cancer patiens, nurses and physicians. Eur J Oncol Nurs, 12, 97-102.

Ramirez LY, Huestis SE, Yap TY, et al (2009). Potential chemotherapy side effects; what do oncologists tell parents? Pediatr Blood Cancer, 52, 497-502.

Sadruddin MM, Hameed-ur-Rehman M (2013). Understanding the perception of children battling cancer about self and others through drawing. South Asia J Cancer, 2, 113-18.

Sheng-Yu F, Eiser C (2009). Body image of children and adolescents with cancer: A systematic review. Body Image, 6, 247-56.

Sitaresmi MN, Mostert S, Purwanto I, et al (2009). Chemotherapyrelated side effects in childhood acute lymphoblastic leukemia in Indonesia: parental perceptions. J Pediatr Oncol Nurs, 26, 198-207

Trüeb R.M (2010). Chemotherapy-induced alopecia. Curr Opin Support Palliat Care, 4, 281-84.

Williamson H, Harcourt D, Halliwell E, Frith H, Wallace M (2010). Adolescents' and parents' experiences of managing psychosocial impact of appearance change during cancer treatment. J Pediatr Oncol Nurs, 27, 168-75.

Zannini L, Verderame F, Cucchiara G, et al (2012). 'My wig has been my journey's companion': perceived effects on aesthetic care programme for Italian women suffering from chemotherapy induced-alopecia. Eur J Cancer Care, 21, 650-60. 